REVISTA X, Curitiba, volume 14, n.3,105-120, 2019.

\title{
O ENSINO DE LITERATURA NA ESCOLA: RETROSPECTIVA E DESAFIOS
}

The Teaching Of Literature In School: Retrospective And Challenges

\author{
Lucas Leal TEIXEIRA (UFVJM) ${ }^{1}$ \\ Noemi Campos Freitas VIEIRA (UFVJM) ${ }^{2}$ \\ Simone Maria de Oliveira Coelho e SALES (UFVJM) ${ }^{3}$
}

\begin{abstract}
RESUMO: O presente artigo se propõe a uma discussão sobre o lugar da literatura na escola. Parte, primeiramente, de uma reflexão sobre o potencial da literatura enquanto instrumento de crítica e reflexão, que propicia ao leitor uma experiência singular com a linguagem. Neste contexto, buscou-se entender como a literatura foi abordada ao longo do tempo na escola, até assumir caráter meramente didático, deixando de lado sua possibilidade de leitura enquanto fruição. Como alternativa a essa excessiva pedagogização da literatura, é que se multiplicaram recentemente as discussões sobre o letramento literário, uma via possível para o ensino de literatura que busca a autonomia do leitor e o prazer do texto. Dessa forma, a literatura deixaria de ser vista apenas em seu caráter de obrigatoriedade e, em alguns casos, até de deslocamento no tempo, para assumir sua verdadeira função: a de emancipadora de consciências por meio de sua configuração particular da linguagem.
\end{abstract}

PALAVRAS-CHAVE: Leitura; letramento literário; escola.

ABSTRACT: This article is a discussion of the place of literature in school. First, it analyzes the potential of literature as a critical instrument of criticism and reflection, which gives the reader a unique experience with a language. This context, we sought to understand how literature is approached in schools, in a purely didactic character, leaving aside its own possibility of action as a fruition. As an alternative to the pedagogization of literature, discussions about literary literacy has been recently multiplied, since the idea of teaching literature in order to get reader autonomy as well as pleasure with the text. In this way, literature is no longer seen in its obligatory character and even, in some cases, in timeless displacement, but as an emancipation of consciousness through its particular configuration of language.

KEYWORDS: Reading; literary literature; school.

\section{INTRODUÇÃO}

A relação entre literatura e escola não é recente. Como todas as outras características sociais, sofreu alterações do tempo em que se inseriu. A literatura na escola não passou incólume às mudanças das eras e costumes, tendo acompanhado as

\footnotetext{
${ }^{1}$ Mestre em Educação pela UFVJM. Email: lucas.teixeira@ifnmg.edu.br

2 Doutora e professora no curso Licenciatura em Educação do Campo, área Linguagens e Códigos Literatura, na Faculdade Interdisciplinar em Humanidades (FIH), da UFVJM. Email: noemiacfv@gmail.com

${ }^{3}$ Graduada em Letras e mestranda na UFVJM. Email: simone.tozinha@gmail.com
} 
REVISTA X, Curitiba, volume 14, n.3,105-120, 2019.

variações do pensamento humano. Ao se pensar na contemporaneidade, a literatura parece ter assumido, em alguns casos, posição secundária, principalmente, no espaço escolar. Mudou a relação do leitor com os livros como também parece ter mudado o lugar que a obra literária ocupa nas aulas. Preocupados com esse novo lócus da literatura na escola, diversos teóricos, principalmente Cosson $(2014,2016)$, puseram-se a pensar e discorrer sobre o letramento literário, que propõe uma abordagem que desvincule o texto literário de um caráter puramente mnemônico e instrumental, permitindo recuperar a primazia da literatura enquanto expressão singular da linguagem.

A importância da literatura não passou despercebida ao longo dos tempos. Já no século XX, em ensaio de 1988, fruto de uma conferência proferida sobre Direitos humanos e Literatura, Antonio Candido (2011) apontou o distintivo caráter humanizador da literatura, enquanto instrumento que possibilita o pleno desenvolvimento das faculdades humanas. Inspirados, pois, por esse afinco de defesa irrestrita da literatura enquanto item básico para a sobrevivência da humanidade, os postulantes do letramento literário advogam nesta prática a possibilidade de proporcionar aos educandos uma experiência mais viva com a linguagem. Assim sendo, neste texto, se discorrerá sobre a importância da literatura, seu lugar na escola e as características do letramento literário.

\section{A IMPORTÂNCIA DA LITERATURA NA ESCOLA}

A leitura literária se apresenta como requisito fundamental à formação dos indivíduos. Faz parte do lastro cultural, ao qual todos os cidadãos devem ter acesso. $\mathrm{O}$ crítico Antonio Candido aponta os benefícios da literatura, tanto para a formação individual do leitor quanto para sua inserção no mundo da cultura letrada e do pensamento: "a literatura corresponde a uma necessidade universal que deve ser satisfeita sob pena de mutilar a personalidade, porque pelo fato de dar forma aos sentimentos e à visão do mundo ela nos organiza, nos liberta do caos e portanto nos humaniza." (CANDIDO, 2011, p. 186).

A fala acima evidencia a complexidade dos saberes e relações permitidos pela literatura. Dessa forma, pelas possibilidades que representa, é um direito universal, muito embora esteja ausente na vida de muitos cidadãos. A literatura permite estabelecer pontes entre o homem e o mundo ou entre o homem e seu semelhante. Esse processo resulta na humanização, entendida como mecanismo que favorece traços 
REVISTA X, Curitiba, volume 14, n. $3,105-120,2019$.

essenciais no homem, tais como a reflexão, desenvolvimento emocional, apuração estética, entre outros (CANDIDO, 2011).

Diversos autores, literários ou não, ressaltaram a importância e o valor da literatura. Guimarães Rosa revela que "às vezes, quase sempre, um livro é maior do que a gente" (ROSA, 1967 apud MACIEL, 2010, p. 11). Em outro momento, Alberto Manguel destacaria que o livro é um lugar de refúgio (MACIEL, 2010, p. 11). Dessa maneira, a leitura literária é compreendida como de suma importância tanto para a vida individual como também social. Permite pensar sobre a existência e discutir problemas em comum, dando ao leitor a oportunidade de fazer um intercâmbio de saberes com o livro e seus pares.

Assim, em muitos casos, a literatura parece não estar cumprindo na escola o já citado aspecto humanizador. A escola é um lócus fértil para a abordagem do objeto literário: "a leitura literária tem a função de nos ajudar a ler melhor [...] porque nos fornece, como nenhum outro tipo de leitura faz, os instrumentos necessários para conhecer e articular com proficiência o mundo feito linguagem." (COSSON, 2016, p. 30). Destacam-se, mais uma vez, as possibilidades de construção da linguagem por meio da literatura. Nesse sentido, a literatura forneceria instrumentos para o exercício crítico e a inserção no mundo das palavras e sentidos, sendo a escola de fundamental importância para o fomento desse processo.

Dado o nível de importância da literatura na escola, pode-se falar em "pedagogia da leitura" (SILVA, 1987, p. 45 apud MAIA, 2007, p. 28). A expressão permite entender a importância da leitura no processo educativo como um todo, sendo que o ato de ler "é uma atividade necessária não só ao projeto educacional do indivíduo, mas também ao projeto existencial, e que, além de ser um ato que se realiza no âmbito da cognição, apresenta caráter social, histórico e político” (MAIA, 2007, p. 29). Dessa forma, a leitura literária atende, pelo menos, duas grandes necessidades: a educacional e a existencial. Por meio da leitura, o indivíduo se forma tanto do ponto de vista cognitivo bem como de seus sentimentos e emoções.

Não obstante o papel da literatura na escola, carece ser feita de maneira distinta de algumas práticas efetuadas até então, por meio do letramento literário. O pressuposto básico que subjaz ao letramento literário é a interação, em um processo no qual os alunos são sujeitos de sua leitura e têm expressão ativa diante dos textos aos quais são apresentados: “[...] tornar-se sujeito das próprias leituras significa não fazer mais parte 
REVISTA X, Curitiba, volume 14, n.3,105-120, 2019.

do jogo de simular leituras; significa, antes de tudo, fazer parte de um outro jogo - o de formar alunos-sujeitos das próprias leituras" (MAIA, 2007, p. 43).

Assim sendo, e reconhecendo o lugar privilegiado da escola no acesso à cultura letrada, as escolas se constituem em espaços nos quais a leitura pode assumir sua verdadeira face: a da libertação, conscientização e construção do exercício crítico. Importa, pois, buscar a gradual substituição do automatismo e simulação de leituras pelo acesso detido e reflexivo às obras literárias, buscando estabelecer, por meio delas, pontes entre o mundo da leitura e o mundo dos educandos.

\section{BREVES APONTAMENTOS SOBRE O ENSINO DE LITERATURA NA ESCOLA}

Sabe-se que a leitura é de fundamental importância para a formação do sujeito, induzindo-o a observar a sociedade, o seu cotidiano, matizando visões e interpretações sobre a humanidade, com relação à vida em si mesma. Segundo Solé (1998, p. 22), "a leitura é um processo de interação entre o leitor e o texto; e neste processo tenta-se satisfazer [obter uma informação pertinente para] os objetivos que guiam sua leitura".

Considerando as dificuldades que a população apresenta quanto ao acesso aos livros e a falta de hábito de ler obras literárias, a escola constitui-se em um lugar especial e apropriado para as práticas de letramento. Para Magda Soares, a escola deve promover o letramento literário de forma a estimular a leitura.

É função e obrigação da escola dar amplo e irrestrito acesso ao mundo da leitura, e isto inclui a leitura informativa, mas também a leitura literária; a leitura para fins pragmáticos, mas também a leitura de fruição; a leitura que situações da vida real exigem, mas também a leitura que nos permita escapar por alguns momentos da vida real (SOARES, 2008, p. 33).

No entanto, no Brasil, há muitos professores que apresentam dificuldades em trabalhar a literatura na escola, não sabem como fazer com que os alunos despertem o gosto pela leitura literária de forma a garantir o conhecimento necessário a todo indivíduo. É imprescindível que as escolas adotem práticas de leitura efetiva de textos, mas que esses não sejam apenas textos informativos ou fragmentos de textos literários usados nas aulas de gramática, e sim desenvolver práticas de acordo com os objetivos para a formação de sujeitos críticos e criativos, explicitando a importância da literatura no contexto escolar.

Desde a infância, a iniciação literária possibilita ao indivíduo a fruição e o prazer, que contribui para o enriquecimento de seu repertório imaginativo, permitindo 
REVISTA X, Curitiba, volume 14, n.3,105-120, 2019.

com essa experiência, a ampliação do conhecimento de mundo, superando seu espaço limitado como arcabouço cultural. Esse alicerce auxilia nas interpretações e atribuição de sentido por parte do leitor, contribuindo para a criticidade deste diante do texto. Assim, de acordo com Coelho (2000, p. 20)

\begin{abstract}
a escola é, hoje, o espaço privilegiado, em que deverão ser lançados as bases para a formação do indivíduo. E, nesse espaço, privilegiamos os estudos literários, pois de maneira mais abrangente do que quaisquer outros, eles estimulam o exercício da mente; a percepção do real em suas múltiplas significações; a consciência do eu em relação ao outro; a leitura em seus vários níveis e, principalmente, dinamizam o estado e conhecimento da língua, da expressão verbal significativa e consciente - condição para a plena realidade do ser (COELHO, 2000, p. 20).
\end{abstract}

Partindo dessa proposição é que os mediadores de leitura se apresentam como agentes principais de intermédio entre o leitor e o texto. Esses são os que vão delinear o trajeto que o sujeito/leitor irá percorrer. Por essa razão, é de grande relevância que todos como: pais, professores, bibliotecários e agentes culturais envolvidos na vida desses alunos tenham consciência da sua função formadora, para que essas práticas não sejam unicamente técnicas.

Cabe aos mediadores, ainda, conduzir o leitor a alcançar o texto, compreender, dialogar e discorrer sobre o que leu. O aluno/leitor não deve ser um indivíduo passivo diante da leitura, mas precisa determinar "[...] uma relação de troca, uma experiência que o leve a se questionar, duvidar, crer e tecer novas concepções acerca do que leu" (BURLAMAQUE, MARTINS; ARAÚJO, 2011, p. 76).

Para que se entenda a importância da literatura na escola é pertinente saber a sua construção histórica. Dessa forma, serão apresentados a priori alguns aspectos notáveis da história da literatura. Embora a literatura pareça desempenhar "um papel considerado subsidiário ou mesmo dispensável” (GALLIAN, 2017, p. 59), houve um tempo em que ela se constituiu "em elemento central na estruturação da cultura das sociedades e na formação de seus indivíduos" (GALLIAN, 2017, p. 59). É interessante notar a relação literatura e sociedade que se estabeleceu desde o princípio, já que o objeto literário, embora não possuísse a configuração atual, servia para a expressão do homem diante da vastidão do mundo.

Gallian (2017) segue afirmando que, ao se retroceder no tempo, deve-se falar em narrativa e não em literatura. A narrativa começaria oral, passando depois, a coexistir ou não com a escrita. As narrativas representam um instrumento de afirmação da identidade de um povo, a exemplo dos hebreus, conforme cita o autor. Os hebreus, por meio dos livros da 
REVISTA X, Curitiba, volume 14, n.3,105-120, 2019.

Bíblia, têm descrita a sua relação com Deus, partícipes de uma aliança e escolhidos para um propósito. De acordo com Eliade apud Gallian (2017), todas as comunidades possuem um mito de origem, sendo que os jovens eram levados a declamarem ou estudarem os textos que contavam a história de seu povo.

É na Grécia, segundo Jaeger apud Gallian (2017), que a literatura assume função principal na educação. Os jovens na Grécia Antiga eram formados a partir dos exemplos e virtudes contidos na Ilíada e na Odisseia. De acordo com Zilberman (2006), entre uma guerra e outra, a literatura que na antiga Grécia se denominava como Poesia, era considerada como ferramenta para o entretenimento da nobreza. Sua forma de apresentação era oral, narrada por pessoas vistas como profissionais da palavra.

Após muitos anos, a Poesia passou a se chamar literatura, que hoje todos conhecem; apesar do nome ter mudado, o seu sentido predomina até os dias atuais. Desde sua origem, a Poesia adquiriu também um caráter educativo, tanto que esta não era somente utilizada em festivais de declamação preparados pela nobreza, mas também em benefício das sociedades feudais como forma de viabilizar padrões à comunidade. Ainda conforme Zilberman (2006, p. 18), "uma certeza, contudo, mantêm-se com o tempo: a de que o texto poético favorece a formação do indivíduo, cabendo, pois, expôlo à matéria-prima literária, requisito indispensável a seu aprimoramento intelectual e ético".

Não se pode deixar de mencionar a relação entre leitura/literatura que se estabeleceu a partir da Igreja, na Idade Média. Segundo Knuppel (2006), as atividades de leitura eram conduzidas nos mosteiros, por meio da leitura em voz alta de salmos. A interpretação da leitura dos salmos deveria ser executada à luz dos pressupostos da religião católica, não havendo espaço para uma interpretação plural. Dessa forma, a leitura possuía forte caráter religioso, o qual determinava os princípios de interpretação. É somente no século $\mathrm{X}$ que o leitor adquire relativa autonomia frente aos livros, podendo lê-los de maneira mais livre e menos controlada.

Ressalte-se, porém, a desconfiança da igreja frente a essa leitura nãodirecionada: [...]“tal procedimento era sinônimo de ociosidade, pois a leitura silenciosa abria espaço para sonhar acordado, para o perigo da preguiça - o pecado da ociosidade, além do perigo de se ler refletindo sobre o sentido das palavras, sem ter alguém que oriente ou que condene a leitura feita" (KNUPPEL, p.6,2006). Observa-se que a leitura feita fora dos muros da igreja, que não se prende a mecanismos da ideologia religiosa, é vista com desconfiança. A literatura, pois, passa a ser vista como "perigosa", na medida 
REVISTA X, Curitiba, volume 14, n.3,105-120, 2019.

em que os resultados à sua exposição não poderiam ser controlados.

Nessa sentido, é bom lembrar da literatura do Renascimento que enfatizou de forma individual, as personalidades. Novas configurações, como os ensaios e as biografias, tornaram-se muito relevantes. A literatura nesse período foi marcada por uma grande critica social em suas obras literárias e no aspecto anticlerical, inúmeras obras criticava a Igreja católica, sendo favorecida pelo a invenção da imprensa por Johann Gutenberg, em 1450, fator importante e revolucionário no âmbito da leitura e escrita, pois foi o início da disseminação das obras clássicas, das renascentistas e dos ideais humanistas do Renascimento literário.

Durante a Renascença, em um aprofundamento de um movimento já iniciado na Idade Média, a ligação literatura e ouvinte perdeu o cunho comunitário e público, voltando-se mais a um aspecto individual e particular. Essas transformações trouxeram grandes impactos para os estados ainda em formação, que não conseguiram mais controlar as pessoas através da literatura e atribuíram para a escola o caráter pedagógico de ensinar (ZILBERMAN, 2006).

Com isso, a escola deixa de ser um lugar opcional para o ensino e passa a ser uma atividade obrigatória. Em seu currículo, porém, ainda não estava a literatura. Apesar de ser primordial para a época, foi somente após a revolução de 1789 que a França introduziu "na escola a literatura nacional, que, a partir de então, torna-se objeto da história literária, disciplina que ensaia seus primeiros passos nesse momento e consolida-se algumas décadas depois em toda Europa para reinar inconteste por muitos anos" (ZILBERMAN, 2016, p. 19).

Desde então, o ensino da literatura na escola passa a ser fundamental, tornandose histórico:

Unido ao currículo escolar, o ensino da literatura oscila entre dois objetivos: ajuda a conhecer a norma linguística nacional, de que é simultaneamente a expressão mais credenciada; arranjada segundo eixo cronológico, responde por uma história que coincide com a história do país de quem toma o nome e cuja existência acaba por comprovar. (ZILBERMAN, 2006, p. 20).

O traço educativo da literatura contribui para uma extensão que transcende os textos poéticos. A literatura na escola demanda ainda particularidades relevantes como a formação da língua e da cultura de uma dada sociedade. Até o século XVII, os textos literários não eram produzidos separadamente para adultos e crianças. Somente a partir do século XVIII, que despertam os olhares para as crianças como diferentes dos adultos. Com o tempo, a escola foi se transformando num sistema educativo organizado e 
REVISTA X, Curitiba, volume 14, n.3,105-120, 2019.

designado a proporcionar à crianças e jovens educação e formação.

A literatura, inclusive, foi escolarizada com potente caráter pedagógico e até nos dias de hoje são vivenciadas marcas dessa pedagogização dos livros, tanto que se verifica um gigantesco e potente mercado editorial de literatura voltado para o público infantil e juvenil. Com relação a isso, Maria da Glória Bordini (1998, p.3) salienta que:

\begin{abstract}
A produção cultural começa a padecer da doença do seu contexto: querendose emancipatória, literária, não obstante depende dos mecanismos do mercado. Torna-se bem de consumo, a ser propagado, para a sobrevivência da indústria e dos produtos culturais, da mesma forma que outros produtos, ou seja, dirigindo-se para necessidades reais ou criando na maioria das vezes necessidades artificiais, para aplicá-las, com a consequente perda de sentido crítico (BORDINI, 1998, p.3).
\end{abstract}

Sobre a literatura na contemporaneidade, as palavras acima abordam uma importante problemática, a subordinação da literatura às leis de mercado, representada pela abrangente difusão de livros, encarada como mais uma necessidade de consumo. Por vezes, os livros perdem seu caráter crítico e reflexivo, na medida em que representam apenas mais um produto a ser comercializado, alijados de uma discussão que debata seu verdadeiro sentido. Tendo a última citação por mediadora, percebe-se que a crescente venda de livros não significa, necessariamente, uma imersão na leitura e o estabelecimento do verdadeiro potencial da literatura.

Outro aspecto da leitura literária na contemporaneidade é que a literatura de modo geral assume uma finalidade estética em busca da formação do leitor. De acordo com Burlamaque, Martins e Araújo (2011, p. 80), “o livro, nesse contexto, só é literatura se a função estética se sobressair à função pedagógica, pois somente o prazer derivado do texto literário, além de proporcionar ao leitor a capacidade de sonhar e imaginar, o emancipa”.

A função estética possibilita à criança o gozo e o prazer de ler, a fruição do texto e, sobretudo, o alargamento dos horizontes de expectativas com intuito de evoluir suas experiências de vida. A literatura infantil e juvenil é necessária pois tem o papel de instigar e nutrir a imaginação do leitor, auxiliando-o a compreender com mais apreço a natureza do seu eu, possibilitando, assim, expandir sua visão de mundo e desenvolver seus horizontes cognitivos e emocionais.

No primeiro contato, a literatura introduz a criança na palavra, no ritmo e na memória, promovendo a competência literária, cuja formação se dá pelo hábito de ler. Oportuniza, ainda, a atuação do indivíduo como leitor aguçando a sua criticidade, 
REVISTA X, Curitiba, volume 14, n. $3,105-120,2019$.

reflexão, capaz de engendrar suas próprias interpretações, além de contribuir na criação dos símbolos e validar o conjunto de crenças e valores.

Para as autoras Burlamaque, Martins e Araújo (2011), a literatura de cunho formador faz com que as crianças contemplem o sentido da arte literária, permitindo uma correspondência com o seu dia a dia. Nas palavras das autoras, "quanto mais oferecemos literatura para as crianças, mais elas estarão capacitadas a entender o texto, a interpretar, a valorizar e a ativar seus intertextos constituídos para o desenvolvimento de uma competência literária.” (BURLAMAQUE; MARTINS; ARAÚJO, 2011, p.81).

A literatura infantil e juvenil, conforme Colomer (2003, p.59) se "define em função do seu destinatário e responde aos propósitos sociais, que lhe foram atribuídos em cada momento histórico". Assim, para descrever a literatura infantil "é preciso antes delimitar o processo de mudança, através do qual esta literatura se adapta a seus destinatários e as variações das funções que se lhe atribuem em cada período histórico".

A escola precisa ensinar o conteúdo de literatura, pois promove a reflexão sobre o mundo, cria realidades, alarga o repertório de linguagem formando leitores preparados para a fruição de obras literárias, entre outras habilidades. É o que defende a espanhola Teresa Colomer (2007), esclarecendo a relevância de ligar leitura, literatura infantil e juvenil e formação literária na sala de aula:

Formar os alunos como cidadãos da cultura escrita é um dos principais objetivos educativos da escola. Dentro desse propósito geral, a finalidade da educação literária "pode resumir-se à formação do leitor competente" [...] o debate sobre o ensino da literatura se superpõe, assim, ao da literatura, já que o que a escola deve ensinar, mais do que "literatura", é " ler literatura". (COLOMER, 2007, p. 30).

Ainda conforme Colomer (2007), o papel da educação literária é, principalmente, favorecer a formação do indivíduo, uma formação que está amarrada de forma sólida à construção da civilidade e "realizada através de confrontação com textos que explicitam a forma em que as gerações anteriores e as contemporâneas abordaram a avaliação da atividade humana através da linguagem." (COLOMER, 2007, p. 31).

Nota-se, hoje, o aumento da circulação dos textos infantil e juvenil dentro da escola, ainda que a ascensão desses textos literários tenha, na maioria das vezes, o propósito voltado para a atividade didática e troca de informação. A escola é o lugar de encontro entre criança e livro; aquela fica, dessa forma, com a responsabilidade de introduzir a criança no mundo da leitura e, principalmente, transformar esses novos leitores em leitores ativos, interessados e proficientes. 
REVISTA X, Curitiba, volume 14, n.3,105-120, 2019.

Como já afirmado nas linhas anteriores, Magda Soares (2008) menciona que é obrigação da escola proporcionar à criança um amplo acesso ao mundo da leitura, tanto a leitura informativa quanto a literária, a leitura com finalidade pragmática como também de fruição.

No entanto, nota-se, em relação ao material escolhido e manipulado pelos professores para iniciação do leitor e incentivo à leitura, que, possivelmente, por falta de formação específica, os mediadores acabam, muitas vezes, aplicando o material simplesmente com finalidades pedagógicas ou utilitárias. Os livros paradidáticos são muito usados nas escolas por terem traços utilitaristas, ou seja, com objetivo ligado à escola. Nesse sentido, o livro paradidático suprime a experiência estética, trata seus leitores de maneira uniforme e possui uma metodologia determinada de trabalho. Com isso, a intenção é que os leitores façam uma única interpretação do texto lido. É muito comum fazer fichas de leituras, preparadas pelos autores ou especialistas para serem preenchidas pelos leitores.

A literatura vem materializando o espaço da leitura na escola enquanto formação de leitores; assim, torna-se imprescindível que o professor não conceda a todos os gêneros textuais um cunho utilitário, porque o prazer de ler está vinculado ao prazer de criar novas situações, penetrando por intermédio das narrativas, numa outra dimensão, num mundo de sonhos e atuações dos personagens. Por meio dessas experiências de leitura, é possível desvelar preconceitos, ligando fatos com sua própria existência, pensando assim, uma forma de tornar o mundo compreensível e mais humano. A literatura, quando nos coloca em conexão com diferentes pontos de vista em relação ao mundo, fornece condições para o crescimento pessoal, e possibilita a formação de métodos específicos para verificar seus próprios sentimentos e ações (CAGNETI; ZOTZ, 1986).

\section{UM CAMINHO PARA O ENSINO DE LITERATURA}

Como já apontado nas discussões anteriores, o letramento literário se apresenta como alternativa ao ensino de literatura. A estrutura do termo letramento pressupõe ação, indicando o ato de alguém se tornar letrado (COENGA, 2010, p. 54). Consoante às novas perspectivas sobre o tema, o letramento vai além do aprendizado da decodificação de signos linguísticos. Implica o aprendizado e uso de estratégias para compreensão de qualquer forma de comunicação. Diariamente, somos submetidos 
REVISTA X, Curitiba, volume 14, n. $3,105-120,2019$.

submetidos a situações comunicativas que requerem a mobilização de habilidades específicas. Ao perscrutar a origem latina do termo letramento, este é definido como

o estado ou condição que assume aquele que aprende a ler e escrever. Implícita nesse conceito está a idéia de que a escrita traz consequências sociais, culturais, políticas, econômicas, cognitivas, linguísticas, quer para o grupo social em que seja introduzida, quer para o indivíduo que aprenda a usá-la. [...] do ponto de vista individual, o aprender a ler e escrever alfabetizar-se, deixar de ser analfabeto, tornar-se alfabetizado, adquirir a "tecnologia" do ler e escrever e envolver-se nas práticas sociais de leitura e de escrita - tem consequências sobre o indivíduo e altera seu estado ou condição em aspectos sociais, psíquicos, culturais, políticos, cognitivos, linguísticos e até mesmo econômicos. (SOARES, 1999, p. 17, 18).

A atual concepção de letramento entende que as situações de escrita e leitura envolvem não só a emissão isolada de um indivíduo, mas que elas se ligam ao contexto no qual a situação comunicativa se processa. Nesse sentido, aprender a ler, escrever e se comunicar como um todo insere o sujeito em uma cadeia de sentidos, tornando-o parte da cultura e integrando-o ao conhecimento. Angela Kleiman cita o termo "empowerment throug literacy" (KLEIMAN, 1995, p. 8), que expressa a possibilidade de aprendizagem e domínio no campo da leitura e escrita que permita não apenas a decodificação, mas também a reconstrução e ampliação dos sentidos. O que se percebe é que a escola, ao longo de sua história, considerou apenas o letramento enquanto categorização de alfabetizado/não alfabetizado.

O letramento apresenta, como uma de suas faces, a abordagem do objeto literário, cujas possibilidades interpretativas podem contribuir à formação e experiência do leitor. Entende-se por letramento literário o trabalho com a literatura que compreenda suas especificidades e permita ao leitor uma experiência singular com a linguagem. O letramento literário defende a possibilidade de uso da literatura que vá além da simples leitura, proporcionando a interação entre a realidade do leitor e as questões abordadas na obra. A esse respeito, Cosson defende a leitura literária com os alunos como

uma prática significativa para eles e para a comunidade em que estão inseridos, uma prática que tenha como sustentação a própria força da literatura, sua capacidade de nos ajudar a dizer o mundo e nos dizer a nós mesmos. Uma prática, em suma, que tenha como princípio e fim o letramento literário. (COSSON, 2016, p. 46).

Dessa forma, a importância da literatura e sua abordagem em sala de aula reside no fato de que possibilita ao homem a expressão de seus sentimentos e opiniões, revelando o mundo por meio das palavras. Cabe ao professor explorar toda a 
REVISTA X, Curitiba, volume 14, n. $3,105-120,2019$.

potencialidade do texto literário, dadas as probabilidades de aproximação do mundo e do indivíduo fornecidas pela literatura. O letramento literário tem como proposição principal a construção da leitura a partir do leitor, envolvido nos diferentes gêneros e se posicionando em relação ao que lê. Ressalte-se que

\begin{abstract}
Aprende-se a ler/escrever, não a partir de treinos mecânicos, repetições e modelos sem sentido, mas a partir de situações concretas, em que o aluno sabe o que está fazendo, para quê e para quem o faz. Só assim é capaz de atribuir um significado ao que lê e escreve e, dessa forma, desenvolver suas estratégias de leitor/produtor de texto (GIROTTO; REVOREDO, 2011, p. 191).
\end{abstract}

Um dos termos que se atribuem ao letramento literário é precisamente "significado", como se viu acima. Isto é, uma leitura que se efetiva como parte de uma prática pedagógica, criativamente estimulada e que possibilita a construção do leitor perante $\mathrm{o}$ ato de ler. A mecanicidade da leitura enquanto prática pouco ou nada contribui para a formação de leitores críticos, que possam ser introduzidos nos protocolos da leitura literária.

Nessa perspectiva, o letramento literário deve ser entendido como processo, abrangendo tanto a individualidade do leitor quanto sua inserção na comunidade leitora. Segundo Cosson (2014), por meio da leitura literária, o leitor, a um só tempo, desenvolve habilidades relacionadas à compreensão/significação do texto, bem como pode interagir com outros alunos leitores. Algumas questões subjazem ao letramento literário, as quais serão pontuadas abaixo:

a) Entendimento da leitura enquanto diálogo: em outras palavras, o ato de ler mobiliza o circuito leitor/autor/texto/contexto. Cosson (2014) afirma que

\footnotetext{
ler é sempre um processo relacional, quer seja entendido como uma relação essencialmente especular [...], quer seja visto como uma operação complexa que inclui, entre outros aspectos, a condição histórica do leitor e seu horizonte de expectativas, as condições de produção do texto, as restrições impostas pela estrutura do texto ao leitor e o contrato enunciativo [...]. (COSSON, 2014, p. 51).
}

Assim, considerar a leitura literária na escola implica percebê-la como um campo para o qual concorrem vários fatores a serem considerados no momento de apreciação do texto. Dentre esses fatores, o próprio lugar do leitor na história da humanidade, incluindo a contemporaneidade, deve ser considerado. A maneira como os leitores encaram o texto literário e a forma como este tem circulado na sociedade vêm mudando ao longo do tempo. Na era da pós-modernidade, após séculos sob a égide da imprensa, pensava-se que o livro já não teria lugar na sociedade, ante a concorrência 
com a diversidade de mídias. Porém,

Quase 500 anos depois, seu invento continua contrariando muitos teóricos e estudiosos que acreditam no fim da era da imprensa. Um exemplo é do canadense Marshall McLuhan, que, no livro O meio é a mensagem, de 1962, afirmou que o fim da impressão estaria chegando com a chegada forte das imagens. A era agora, segundo ele, seria a audiovisual. Sabemos que não foi assim e, atualmente, vivemos a era da informatização que também não desbancou o poder do impresso. (SANTOS, 2012, p. 18)

O que se percebe, a partir da reflexão acima, é que os livros não foram totalmente apagados da sociedade. Seguem presentes influenciando gerações de leitores. O que mudou, contudo, é a forma como as pessoas se relacionam com a literatura. Há uma tendência para o uso de plataformas eletrônicas, como a leitura de livros digitais. Assim, a própria atividade em sala de aula deve considerar essa nova realidade, na qual os livros interagem com as mídias: "A literatura é chamada, então, não a redefinir sua natureza, mas a explorar recursos disponibilizados por suportes das mídias. Assim, modifica-se a própria fruição do literário. [...] Nesse caso, a literatura é convocada a se expressar não mais em seu formato tradicional de papel impresso". (BULHÕES, 2012, p. 106).

O professor precisa estar atento a essa realidade, com vistas a propiciar momentos de problematização relativos ao modus operandi da leitura. Já no que tange ao texto em si, uma leitura pode ser mais produtiva ao se propor uma imersão nas suas condições/fatores de produção, permitindo ao leitor se situar em relação ao que lê.

b) Valorização do papel do leitor frente ao texto: Cosson (2014) ressalta que a atividade do leitor favorece a constituição do aspecto literário no texto. Assim, a obra literária se plenifica na experiência do leitor frente à obra: a "obra literária, portanto, não existe no texto, mas sim na experiência da leitura feita por determinado leitor localizado em um tempo e espaço específicos" (COSSON, 2014, p. 54). Dessa forma, o letramento literário reafirma o papel do aluno-leitor, que pode se expressar e se posicionar em relação aos textos lidos. Essa é uma postura que difere em muito de um ensino voltado apenas à resolução de questões com respostas predeterminadas e análises que não permitam também a livre expressão do leitor.

c) Concepção da literatura como instrumento de múltiplas visões sobre a realidade: o letramento literário entende a literatura como uma espécie de lupa sobre a qual se pode ver o mundo. Por isso mesmo, os textos não podem ser simplesmente dispensados sob a alegação de que não estão de acordo com os dias atuais. Devem ser 
REVISTA X, Curitiba, volume 14, n.3,105-120, 2019.

lidos com um olhar aguçado, buscando possíveis preconceitos ou pareceres já superados e que possam ser esclarecidos sob o viés do pensamento contemporâneo. Essas discussões também são feitas por Cosson (2014), ao defender o texto literário como instrumento de problematização.

As características acima (entendimento da leitura enquanto diálogo; valorização do papel do leitor frente ao texto; concepção da literatura como instrumento de múltiplas visões sobre a realidade) permitem entender o lugar que o letramento literário concede à literatura na escola. A leitura pela literatura seria o caminho mais fértil para desenvolver habilidades de interpretação, compreensão e expressão. A esse respeito, Cosson (2014) declara que

Como a matéria-prima da literatura é a palavra, o mundo da literatura é, em primeiro e último lugar, linguagem. Dessa forma, a leitura literária demanda do leitor que se debruce sobre o modo de dizer ao mesmo tempo em que se inteira do que é dito. Os recursos expressivos presentes nos textos literários fazem com que o leitor perceba que a linguagem não é transparente [...]. (COSSON, 2014, p. 50)

Consoante a declaração acima, percebe-se que a literatura pode propiciar a inserção no universo das palavras, fazendo com que o leitor, devidamente orientado, compreenda como a língua ajuda a forjar a trama literária. A literatura seria, pois, uma rica e profícua demonstração de como a linguagem se molda e articula em um tempo e contexto específicos, dando origem a histórias e composições singulares.

\section{POSSÍVEIS CONTRIBUIÇÕES}

Por fim, pode-se dizer que a escola é o lugar privilegiado para o acesso da cultura letrada que contribui para o desenvolvimento do indivíduo em muitos aspectos, principalmente, quando se trata da importância da literatura para a formação do sujeito crítico e criativo diante da sociedade. A literatura na escola permite ao sujeito leitor alargar seus horizontes de expectativas por meio da apropriação do texto literário, é um dos pontos mais importantes para a formação do leitor literário. É relevante buscar oportunidades para propiciar uma formação continuada que ofereça aos professores aparatos teórico-metodológicos que contribuam para a transformação das práticas em sala de aula. Com isso, fazer com que o texto literário não sirva apenas como suporte das aulas de língua portuguesa e sim despertar nos alunos o prazer da leitura literária. Além de fazer com que os mediadores da leitura sejam capazes de se direcionar para uma nova prática que desenvolva o trabalho efetivo com a leitura literária na escola. 


\section{REFERÊNCIAS}

BORDINI, M.G. A literatura infantil nos anos 80. In: SERRA, Elizabeth D'Ângelo (Org.). 30 anos de literatura para crianças e jovens: algumas leituras. Campinas; São Paulo. Mercado de Letras: Associação de Leitura do Brasil, 1998.

BULHÕES, M. Mídia e literatura: tematizações, correlativos, conexões. Líbero, v. 15, n. 29, p. 101-110, 2012. Disponível em: > Acesso em: 15 Mai 2019.

BURLAMAQUE, F.V.; MARTINS, K.C.C.; ARAÚJO, M.S. A leitura do livro de imagem na formação do leitor. In: SOUZA, R.J.; FEBA, B.L.T. (Org.). Leitura literária na escola: reflexões e propostas na perspectiva do letramento. Campinas, SP: Mercado de Letras, 2011. p. 75-95.

CAGNETI, S.S.; ZOTZ, W. Livro que te quero livre. Rio de Janeiro: Nórdica, 1986.

CANDIDO, A. O direito à literatura. In: . Vários escritos. Rio de Janeiro: Ouro sobre Azul, 2011. p. 171-193.

COELHO, N.N. Literatura infantil: teoria, análise, didática. São Paulo: Moderna, 2000.

COENGA, R.. Leitura e letramento literário; diálogos. Cuiabá: Carlini e Caniato, 2010.

COLOMER, T.. A Formação do Leitor Literário. São Paulo: Global, 2003.

- Andar entre livros: a leitura literária na escola: [Tradução Laura Sandroni]. São

Paulo: Global, 2007.

COSSON, R. Círculos de leitura e letramento literário. São Paulo: Contexto, 2014. Letramento literário: teoria e prática. São Paulo: Contexto, 2016.

GIROTTO, C.G.G.; REVOREDO, M. Narrativas míticas e a apropriação da leitura escrita literária: uma proposição prática. In: SOUZA, R.J.; FEBA, B.L.T. (Org.). Leitura literária na escola: reflexões e propostas na perspectiva do letramento. São Paulo: Mercado de Letras, 2011. p. 183-212.

KLEIMAN, A.B. (Org.). Os Significados do Letramento: uma nova perspectiva sobre a prática social da escrita. Campinas: Mercado de Letras, 1995.

KNUPPEL, M.A.C. História da leitura: do prólogo à inspiração. In: Vii Seminário Nacional De Estudos E Pesquisas - HISTEDBR, 2006. Navegando na História da Educação Brasileira. UNICAMP, 2006.

Disponível em: <https://document.onl/documents/vii-seminario-nacional-de-estudos-epesquisas-historia-.html> Acesso em: 15 Mai 2019.

MACIEL, F. Educação, leitura e literatura: diálogos possíveis. In: PAIVA, Aparecida; MACIEL, Francisca; COSSON, Rildo (Coord.). Literatura: ensino fundamental. Brasília: Ministério da Educação, 2010. 
REVISTA X, Curitiba, volume 14, n. $3,105-120,2019$.

MAIA, J. Literatura na formação de leitores e professores. São Paulo: Paulinas, 2007. p. 27-46.

SANTOS, A. M. GUTEMBERG: a era da imprensa Percepções | Caçador-SC | v. 1 | n. 1 I jan./jun. 2012. Disponível em:

<https://periodicos.uniarp.edu.br/percepcoes/article/view/25> Acesso em: 15 Mai 2019. ISSN: 2238-9644

SOARES, M. Introdução - Ler, verbo transitivo. In: PAIVA, A.; MARTINS, A.; PAULINO, G.; VERSIANI, Z. (Org.). Leituras Literárias: discursos transitivos. Belo Horizonte: Ceale; Autêntica, 2008.

Letramento: um tema em três gêneros. São Paulo: Autêntica, 1999.

SOLÉ, I. Estratégias de leitura. Trad. Cláudia Schilling. 6.ed. Porto alegre: Artes Médicas, 1998.

ZILBERMAN, R. "Sim, a Literatura Educa". In: ZILBERMAN, R.; SILVA, E. T. Literatura e pedagogia: ponto e contraponto. São Paulo: Global, 2006. 